\title{
Association of bariatric surgery with risk of acute care use for hypertension-related disease in obese adults: population-based self-controlled case series study
}

Yuichi J. Shimada ${ }^{1 *}$, Yusuke Tsugawa ${ }^{2}$, Hiroyasu Iso ${ }^{3}$, David F. M. Brown ${ }^{4}$ and Kohei Hasegawa ${ }^{4}$

\begin{abstract}
Background: Hypertension carries a large societal burden. Obesity is known as a risk factor for hypertension. However, little is known as to whether weight loss interventions reduce the risk of hypertension-related adverse events, such as acute care use (emergency department [ED] visit and/or unplanned hospitalization). We used bariatric surgery as an instrument for investigating the effect of large weight reduction on the risk of acute care use for hypertension-related disease in obese adults with hypertension.

Methods: We performed a self-controlled case series study of obese patients with hypertension who underwent bariatric surgery using population-based ED and inpatient databases that recorded every bariatric surgery, ED visit, and hospitalization in three states (California, Florida, and Nebraska) from 2005 to 2011. The primary outcome was acute care use for hypertension-related disease. We used conditional logistic regression to compare each patient's risk of the outcome event during sequential 12-month periods, using pre-surgery months 13-24 as the reference period.

Results: We identified 980 obese patients with hypertension who underwent bariatric surgery. The median age was 48 years (interquartile range, $40-56$ years), $74 \%$ were female, and $55 \%$ were non-Hispanic white. During the reference period, $17.8 \%$ (95\% confidence interval [Cl], 15.4-20.2\%) had a primary outcome event. The risk remained unchanged in the subsequent 12-month pre-surgery period $(18.2 \%$ [95\% Cl, 15.7-20.6\%]; adjusted odds ratio [aOR] 1.02 [95\% Cl, 0.831.27]; $P=0.83)$. In the first 12 -month period after bariatric surgery, the risk significantly decreased $(10.5 \%$ [8.6-12.4\%]; aOR $0.58[95 \% \mathrm{Cl}, 0.45-0.74] ; P<0.0001)$. Similarly, the risk remained significantly reduced in the 13-24 months after bariatric surgery $(12.9 \%$ [95\% Cl, 10.8-15.0\%]; aOR 0.71 [95\% Cl, 0.57-0.90]; $P=0.005)$. By contrast, there was no significant reduction in the risk among obese patients who underwent non-bariatric surgery (i.e., cholecystectomy, hysterectomy, spinal fusion, or mastectomy).

Conclusions: In this population-based study of obese adults with hypertension, we found that the risk of acute care use for hypertension-related disease decreased by $40 \%$ after bariatric surgery. The data provide the best evidence on the effectiveness of substantial weight loss on hypertension-related morbidities, underscoring the importance of discussing options for weight reduction when treating obese patients with hypertension.
\end{abstract}

Keywords: Bariatric surgery, Emergency department visit, Hospitalization, Hypertension, Obesity, Self-controlled case series study

\footnotetext{
* Correspondence: yshimada@partners.org

${ }^{1}$ Cardiology Division, Department of Medicine, Massachusetts General

Hospital, Harvard Medical School, 55 Fruit Street, Gray/Bigelow 800, Boston,

MA 02114, USA

Full list of author information is available at the end of the article
}

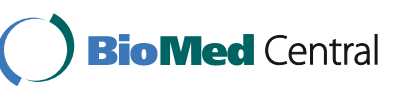

(c) The Author(s). 2017 Open Access This article is distributed under the terms of the Creative Commons Attribution 4.0 International License (http://creativecommons.org/licenses/by/4.0/), which permits unrestricted use, distribution, and reproduction in any medium, provided you give appropriate credit to the original author(s) and the source, provide a link to the Creative Commons license, and indicate if changes were made. The Creative Commons Public Domain Dedication waiver (http://creativecommons.org/publicdomain/zero/1.0/) applies to the data made available in this article, unless otherwise stated. 


\section{Background}

Hypertension (HTN) is the leading public health problem, affecting more than one billion adults worldwide [1]. In the USA, the prevalence of HTN in adults is approximately 33\% (80.0 million Americans) with estimated direct and indirect costs of $\$ 49$ billion in 2012 [2]. Among these patients, blood pressure is uncontrolled in approximately half of them, particularly in obese individuals [3, 4]. HTN accounts for a substantial healthcare utilization, e.g., one million emergency department (ED) visits and 500,000 hospitalizations annually [2]. In parallel, the USA has also experienced an obesity epidemic - 35\% of men and $40 \%$ of women are obese [5]. Significant weight reduction is known to decrease blood pressure and sometimes results in remission of HTN among obese adults [6-10]. Among various weight management strategies, bariatric surgery is the most effective method to achieve substantial and sustained weight loss [11]. However, little is known about the impact of significant weight reduction with bariatric surgery on acute care use (ED visits and/or unplanned hospitalizations) for HTN-related disease [12].

In this context, we aimed to determine whether bariatric surgery, as an instrument to achieve large weight reduction, reduces the risk of acute care use for HTNrelated disease among obese patients with HTN. To do this, we used large longitudinal datasets from three diverse states. A better understanding of the role of bariatric surgery in the prevention of HTN-associated morbidities would provide further insight into therapeutic strategies for obese patients with HTN.

\section{Methods}

\section{Study design and setting}

We performed a self-controlled case series study using the Healthcare Cost and Utilization Project (HCUP) State Emergency Department Databases (SEDD) and State Inpatient Databases (SID) $[13,14]$. The study design was selected because each patient serves as his/her own control; therefore, a separate control group is not necessary [15]. This study performed intra-person comparisons in the patients who experienced both the exposure (bariatric surgery) and the outcome (acute care use for HTN-related disease). Confounding by unmeasured variables was minimized, as all time-invariant covariates (e.g., patient characteristics and genetics) were implicitly controlled [15].

We analyzed the data from HCUP SEDD and SID in three states (California, Florida, and Nebraska) from 2005 to 2011. The HCUP is the largest longitudinal hospital care database in the USA and provides all-payer, encounter-level information [13, 14]. The SEDD records all ED visits including treat-and-release encounters and transfers from short-term, acute-care, and nonfederal hospitals in participating states [13]. The HCUP SID captures all inpatient discharges from short-term, acute- care, nonfederal, general, and other specialty hospitals [14]. Integration of HCUP SEDD and SID enables us to identify all ED visits regardless of disposition and all hospitalizations regardless of the source of hospitalization in the three states $[13,14]$. We chose these three states because they are geographically diverse and have unique patient identifiers that enabled us to perform longitudinal patient follow-up across the study years within the states. Details of the study design, databases, and statistical methods have been published elsewhere [13, 14, 16-19]. The institutional review board of Massachusetts General Hospital approved this study.

\section{Study population}

The following steps were undertaken to identify all obese adults (aged $\geq 18$ years) who underwent bariatric surgery and had an acute care use for HTN-related disease in the three states. First, we identified adults with a diagnosis code for obesity who had at least one hospitalization for bariatric surgery. The International Classification of Diseases, Ninth Revision, Clinical Modification (ICD-9CM) diagnosis codes for obesity were 278.0-278.2, V77.8, V85.3x, and V85.4 [16-20]. The Current Procedural Terminology codes for bariatric surgery were 43.89 , $44.31,44.38,44.39,44.50,44.68,44.69,44.93,44.95$, 44.99, 45.51, and 45.90 [16-20]. We excluded patients who had diagnostic codes for gastrointestinal cancer (ICD-9-CM codes 150.0-159.9) [16-19]. To allow for data collection during the 2-year pre-surgery and postsurgery periods, we included patients who underwent bariatric surgery between 1 January 2007 and 31 December 2009. Second, we further identified patients with HTN, which was defined in the present study as having at least one acute care use for HTN-related disease during the study years, i.e., between 1 January 2005 and 31 December 2011. The ICD-9-CM diagnosis codes for HTN-related disease were 401 (essential hypertension), 402 (hypertensive heart disease), 403 (hypertensive chronic kidney disease), 404 (hypertensive heart and chronic kidney disease), 405 (secondary hypertension), and 437.2 (hypertensive encephalopathy), as the primary diagnosis $[21,22]$. The exclusion criteria were residents outside the three states and patients who died during the hospitalization for bariatric surgery, had an inhospital death during the 2-year post-surgery period, or had multiple bariatric surgeries during the study period. We also excluded planned hospitalizations to examine acute care needs in patients with HTN.

\section{Measurements}

We used the baseline characteristics recorded during the index hospitalization for bariatric surgery. We retrieved demographics data including age, sex, and race/ethnicity (non-Hispanic white, non-Hispanic black, Hispanic, and 
"other"), primary insurance type (Medicare, Medicaid, private sources, and "other"), quartiles for estimated median household income of residents in the patient's ZIP code, ICD-9-CM diagnosis, procedures, disposition, season of surgery, and state.

\section{Statistical analysis}

The primary endpoint was a composite of ED visit or unplanned hospitalization with a primary diagnosis related to HTN during a 4-year period (i.e., 2 years before and 2 years after bariatric surgery). We computed adjusted odds ratios (aORs) with a conditional logistic regression model using pre-surgery months $13-24$ as the reference period for $1-12$ months before surgery, $0-12$ months after surgery, and 13-24 months after surgery. Each patient was matched to his/her own reference period.

We tested the robustness of our inferences by performing several sensitivity analyses. First, we repeated the analysis stratified by age group (18-44, 45-54, and $\geq 55$ years) and sex. Second, we modeled the primary endpoint as a count variable as opposed to a binary outcome with a negative binomial regression model. Third, we repeated the primary model in a subgroup of patients who had at least one acute care use for any reason during post-surgery $25-36$ months. This sensitivity analysis addressed the possibility of loss to follow-up (e.g., outof-hospital deaths, moving out of the study states). This subgroup selection method ensured that these patients were both alive and living within the study states at least until 2 years after surgery and would have been recorded in the databases if they had the primary endpoint during the study period. Fourth, we conducted a sensitivity analysis using a more restrictive definition of the outcome event, i.e., only including the ICD-9-CM diagnosis codes 401 and 437.2. Fifth, we performed the self-controlled case series analysis for four other types of elective surgery: cholecystectomy (Current Procedural Terminology codes 51.21-51.24 and 51.41-51.59), hysterectomy (Current Procedural Terminology codes 68.31-68.79 and 68.9), spinal fusion (Current Procedural Terminology codes 81.00-81.66), and mastectomy (Current Procedural Terminology codes 85.41-85.48) [16, 17]. We performed this analysis to address the possibility that reductions in the risk of acute care use for HTNrelated disease might be observed with any elective surgery in general (e.g., intensified blood pressure control during peri-surgical period). We selected these nonbariatric surgeries because they have a large sample size, similar characteristics (i.e., common elective surgery), and no biological plausibility to affect weight or the risk of acute care use for HTN-related disease. Lastly, to delineate the differential effects of individual types of bariatric surgery on the risk of acute care use for HTN- related disease, we performed separate self-controlled case series analyses for the two most common types of bariatric surgery: gastric bypass (Current Procedural Terminology codes 44.31, 44.38, and 44.39) and gastric banding (Current Procedural Terminology codes 44.68 and 44.95) [23]. All analyses were performed at a twosided significance level of 0.05 , and all confidence intervals (CIs) were reported as two-sided values with a confidence level of $95 \%$. Statistical analyses were performed with SAS version 9.4 (SAS Institute, Cary, NC, USA).

\section{Results}

We identified a total of 1022 obese adults who underwent bariatric surgery between 1 January 2007 and 31 December 2009 and also had at least one ED visit or hospitalization with a primary diagnosis related to HTN between 1 January 2005 and 31 December 2011. From this population, we excluded 18 patients who had an inhospital death within 2 years after bariatric surgery and 26 patients who underwent multiple bariatric surgeries (two patients had both). We included the remaining 980 patients in the primary analysis. Table 1 describes the baseline characteristics at the time of bariatric surgery. The median age was 48 years (interquartile range, 40-56 years), $74 \%$ were female, and $55 \%$ were non-Hispanic white.

Table 2 summarizes the risk of acute care use for HTN-related disease in the pre- and post-bariatric surgery periods. During the reference period (i.e., 13-24 months prior to bariatric surgery), we observed at least one acute care use for HTN-related disease in $17.8 \%$ (95\% CI 15.4-20.2\%) of the study population. The risk did not change in the following 12-month pre-surgery period (18.2\%, 95\% CI 15.7-20.6\%), corresponding to an aOR of 1.02 (95\% CI $0.83-1.27 ; P=0.83$ ). By contrast, we observed a significant decline in the risk after bariatric surgery. Within 12 months after bariatric surgery, 10.5\% (95\% CI 8.6-12.4\%) experienced an acute care use for HTN-related disease (aOR 0.58, 95\% CI 0.45-0.74; $P$ $<0.0001)$. The risk remained significantly reduced during the subsequent period of 13-24 months post-surgery (12.9\%, 95\% CI 10.8-15.0\%), corresponding to an aOR of 0.71 (95\% CI 0.57-0.90; $P=0.005$; Fig. 1).

In the stratification analysis by age group with a limited statistical power, a similar risk reduction was observed in the 18-44 and 45-54 year age groups (Additional file 1). The sensitivity analysis stratified by sex showed that women had a similar reduction in the risk over the 2-year post-surgery period, while men had a significant reduction only in the first 12 months after bariatric surgery (Additional file 2). The sensitivity analysis modeling the outcome as a count variable replicated the findings of the main analysis (Additional file 3). Likewise, the subgroup analysis of patients who had 
Table 1 Baseline characteristics of patients with hypertension who underwent bariatric surgery

\begin{tabular}{|c|c|}
\hline Characteristics & Number $(n)=980$ \\
\hline Age (years), median (IQR) & $48(40-56)$ \\
\hline Female sex & $718(73.6)$ \\
\hline \multicolumn{2}{|l|}{ Race/ethnicity ${ }^{a}$} \\
\hline Non-Hispanic white & $512(54.8)$ \\
\hline Non-Hispanic black & $254(27.2)$ \\
\hline Hispanic & $142(15.2)$ \\
\hline Other & $26(2.8)$ \\
\hline \multicolumn{2}{|l|}{ Primary insurance } \\
\hline Medicare & $240(24.5)$ \\
\hline Medicaid & $108(11.0)$ \\
\hline Private & $560(57.2)$ \\
\hline Other & $71(7.3)$ \\
\hline \multicolumn{2}{|c|}{ Quartiles for median household income of patient's ZIP code } \\
\hline 1 (lowest) & $301(31.1)$ \\
\hline 2 & $265(27.4)$ \\
\hline 3 & $235(24.3)$ \\
\hline 4 (highest) & $167(17.3)$ \\
\hline \multicolumn{2}{|l|}{ Season of bariatric surgery } \\
\hline January-March & $204(20.8)$ \\
\hline April-June & $234(23.9)$ \\
\hline July-September & $281(28.7)$ \\
\hline October-December & $261(26.6)$ \\
\hline \multicolumn{2}{|l|}{ State } \\
\hline California & $600(61.2)$ \\
\hline Florida & $368(37.6)$ \\
\hline Nebraska & $12(1.2)$ \\
\hline
\end{tabular}

Data were expressed as numbers (percentages), unless otherwise indicated. IQR interquartile range

${ }^{a}$ Analyzed for 934 (95.3\%) patients with race/ethnicity data. Race/ethnicity data were not available in Nebraska

any acute care use during 25-36 months after bariatric surgery $(n=325)$ showed, even with a limited statistical power, a similar pattern with a larger effect size (Table 3). The sensitivity analysis using a more restrictive definition of HTN-related disease demonstrated consistent results (Additional file 4). By contrast, in the separate self-controlled case series analyses with obese patients with HTN who underwent cholecystectomy $(n=378)$, hysterectomy $(n=112)$, spinal fusion $(n=61)$, or mastectomy $(n=30)$, the risk of the primary outcome did not decrease after non-bariatric surgery (Table 4). The sensitivity analysis according to the type of bariatric surgery showed that the point estimate of the odds ratio was lower after gastric bypass compared to gastric banding (Additional file 5).

\section{Discussion}

\section{Principal findings}

By using population-based data of patients with HTN who underwent bariatric surgery in the three diverse states, we found that the risk of acute care use for HTNrelated disease decreased by $40 \%$ after bariatric surgery. The observed large decline in the risk remained significant for at least 2 years after surgery. In contrast, other non-bariatric surgeries were not associated with a reduced risk of acute care use for HTN-related disease, addressing the possibility that the observed decrease in the risk might be attributable to intensified blood pressure control during the peri-surgical period.

\section{Results in context}

Several studies have reported that large weight reduction by surgical interventions lowers blood pressure and sometimes leads to remission of HTN [6-10]. However, the inferences from these studies on HTN-related healthcare utilization are potentially limited by the lack of assessment of acute care utilization (e.g., ED visit or hospitalization) related to HTN. By contrast, in the present study, both the population and the outcome are unique, because all patients had at least one ED visit or hospitalization for HTN-related disease, and the risk of such healthcare utilization was assessed. This study adds to the body of knowledge by demonstrating the effectiveness of substantial weight reduction (bariatric surgery as an instrument) on the risk of hospital-based acute care use for HTN-related disease among obese patients with HTN.

Physiological studies in humans have indicated that a substantial weight loss can reverse some of the links between obesity and HTN-related morbidities. For instance, weight loss intervention has been reported to improve blood pressure control with a dose-response relationship [24, 25]. Bariatric surgery has been known to favorably affect endothelial function, systemic inflammation, and oxidative stress [24-28]. Moreover, the present study demonstrated that bariatric surgery was associated with a substantially and persistently lower risk of acute care use for HTN-related disease. Additionally, gastric bypass surgery, which is known to result in a larger weight loss $(\sim 60 \%$ excess weight loss $)$ than gastric banding ( $\sim 35 \%$ excess weight loss) [29], may achieve a larger risk reduction compared to gastric banding. Our data, along with prior evidence, collectively indicate that substantial weight loss may reverse the link between obesity and HTN-related morbidities.

\section{Advantages of the study design}

The self-controlled case series design augments the internal validity, because it eliminates inter-personal variations and enables a precise assessment of impact of the 
Table 2 Number of patients and risk of acute care use for hypertension-related disease

\begin{tabular}{|c|c|c|c|c|}
\hline \multirow[t]{2}{*}{ Time interval and outcome } & Number of patients & Risk, \% (95\% Cl) & $\mathrm{aOR}(95 \% \mathrm{Cl})^{\mathrm{a}}$ & $P$ value \\
\hline & \multicolumn{4}{|l|}{$(n=980)$} \\
\hline \multicolumn{5}{|c|}{ 13-24 months before bariatric surgery } \\
\hline ED visit or hospitalization ${ }^{b}$ & 174 & $17.8(15.4-20.2)$ & Reference & - \\
\hline ED visit ${ }^{c}$ & 130 & $13.3(11.1-15.4)$ & Reference & - \\
\hline Hospitalization $^{d}$ & 44 & $4.5(3.2-5.8)$ & Reference & - \\
\hline \multicolumn{5}{|c|}{ 1-12 months before bariatric surgery } \\
\hline ED visit or hospitalization ${ }^{b}$ & 178 & $18.2(15.7-20.6)$ & $1.02(0.83-1.27)$ & 0.83 \\
\hline ED visit ${ }^{c}$ & 130 & $13.3(11.1-15.4)$ & $1.00(0.78-1.28)$ & 0.99 \\
\hline Hospitalization ${ }^{d}$ & 50 & $5.1(3.7-6.5)$ & $1.14(0.76-1.73)$ & 0.53 \\
\hline \multicolumn{5}{|c|}{ 0-12 months after bariatric surgery } \\
\hline ED visit or hospitalization ${ }^{b}$ & 103 & $10.5(8.6-12.4)$ & $0.58(0.45-0.74)$ & $<0.0001$ \\
\hline ED visit ${ }^{c}$ & 91 & $9.3(7.5-11.1)$ & $0.69(0.53-0.91)$ & 0.008 \\
\hline Hospitalization $^{d}$ & 14 & $1.4(0.7-2.2)$ & $0.31(0.17-0.57)$ & $<0.0001$ \\
\hline \multicolumn{5}{|c|}{ 13-24 months after bariatric surgery } \\
\hline ED visit or hospitalization ${ }^{b}$ & 126 & $12.9(10.8-15.0)$ & $0.71(0.57-0.90)$ & 0.005 \\
\hline ED visit ${ }^{c}$ & 100 & $10.2(8.3-12.1)$ & $0.76(0.58-0.99)$ & 0.04 \\
\hline Hospitalization $^{d}$ & 30 & $3.1(2.0-4.1)$ & $0.68(0.42-1.08)$ & 0.10 \\
\hline
\end{tabular}

$\mathrm{Cl}$ confidence interval, $a O R$ adjusted odds ratio, $E D$ emergency department

${ }^{a}$ Adjusted odds ratios are for each 12-month period versus the reference period (i.e., 13-24 months before the index bariatric surgery), as calculated with conditional logistic regression

${ }^{\mathrm{b}}$ At least one acute care use (ED visit or unplanned hospitalization) for HTN-related disease

${ }^{C}$ At least one ED visit for HTN-related disease, not resulting in hospitalization

${ }^{\mathrm{d}}$ At least one unplanned hospitalization for HTN-related disease

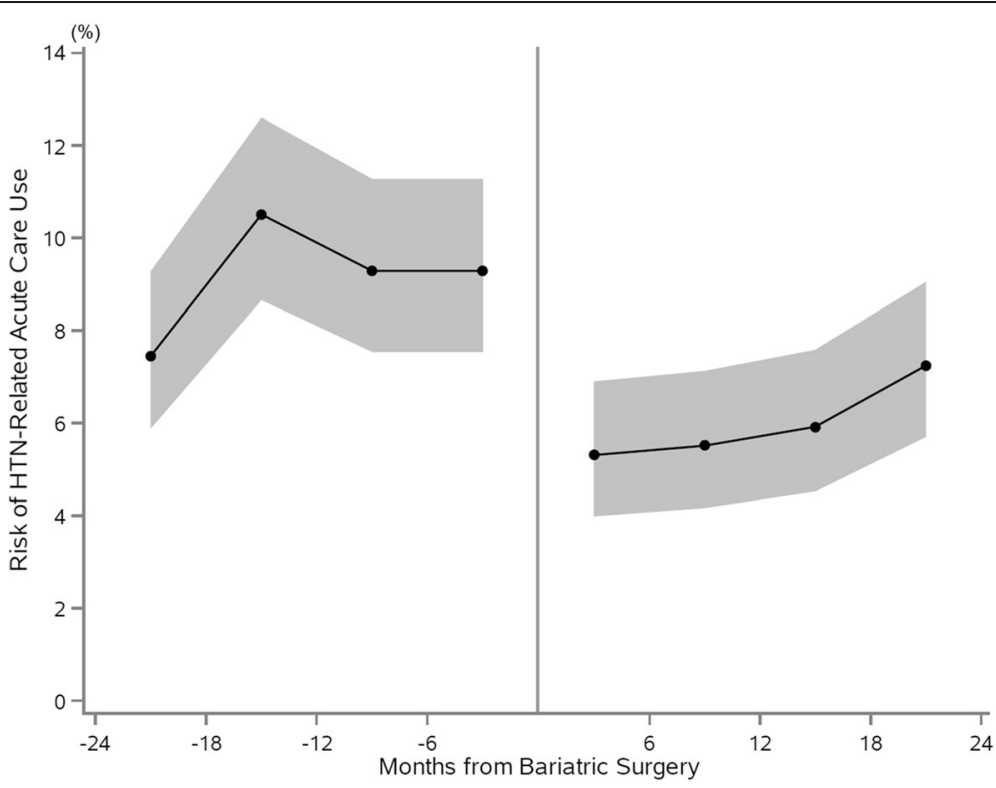

Fig. 1 Risk of acute care use for hypertension-related disease before and after bariatric surgery in a 6-month interval. Shown is the proportion of patients with an acute care use (ED visit and/or unplanned hospitalization) related to HTN with the $95 \%$ Cls for the 2 years before and after bariatric surgery in 6-month intervals. The periods were centered on the date of bariatric surgery of each patient. Cl confidence interval, ED emergency department, HTN hypertension 
Table 3 Number of patients and risk of acute care use for hypertension-related disease, limiting to patients with any healthcare utilization during 25-36 months after bariatric surgery

\begin{tabular}{lllll}
\hline Time interval & $\begin{array}{l}\text { Number of patients } \\
(n=325)\end{array}$ & Risk, \% $(95 \% \mathrm{Cl})^{\mathrm{a}}$ & aOR $(95 \% \mathrm{Cl})^{\mathrm{b}}$ \\
\hline 13-24 months before bariatric surgery & 59 & $18.2(13.9-22.4)$ & Reference \\
1-12 months before bariatric surgery & 52 & $16.0(12.0-20.0)$ & $0.87(0.59-1.29)$ & $0.47(0.30-0.74)$ \\
$0-12$ months after bariatric surgery & 29 & $8.9(5.8-12.0)$ & 0.49 \\
$13-24$ months after bariatric surgery & 41 & $12.6(9.0-16.2)$ & $0.68(0.45-1.02)$ \\
\hline
\end{tabular}

Cl confidence interval, aOR adjusted odds ratio

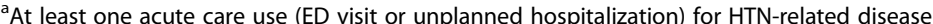

${ }^{b}$ Adjusted odds ratios are for each 12-month period versus the reference period (i.e., 13-24 months before the index bariatric surgery), as calculated with conditional logistic regression

exposure (i.e., bariatric surgery) [15]. In addition, in contrast to the traditional case-control or other cohort study designs, confounding by time-invariant variables (both measured and unmeasured) is addressed, as each subject functions as a control for her/himself [15]. Because of these advantages, the self-controlled case series study design has been successfully used to demonstrate the associations between weight reduction and morbidity in other disease conditions (e.g., congestive heart failure, asthma, and stable angina pectoris) [16-18]. The present study meets the requirements of the self-controlled case series design, because the exposure is transient and discrete and the outcome is an acute event [15].

With regard to the external validity, it has been reported that subjects participating in randomized controlled trials (RCTs) may be highly selected or behave differently compared to the general populations in the real-world setting $[30,31]$. For instance, most of the previously published RCTs on bariatric surgery enrolled $<10 \%$ of the screened patients [32,33]. By contrast, the patients analyzed in the

Table 4 Number of patients and risk of acute care use for hypertension-related disease among obese patients with hypertension who underwent non-bariatric surgery

\begin{tabular}{|c|c|c|c|c|}
\hline Time interval and surgery & Number of patients & Risk, \% $(95 \% \mathrm{Cl})^{\mathrm{a}}$ & $\mathrm{aOR}(95 \% \mathrm{Cl})^{\mathrm{b}}$ & $P$ value \\
\hline Cholecystectomy & $(n=378)$ & & & \\
\hline 13-24 months before surgery & 64 & $16.9(13.1-20.7)$ & Reference & - \\
\hline 1-12 months before surgery & 129 & $34.1(29.3-38.9)$ & $2.13(1.56-2.91)$ & $<0.0001$ \\
\hline 0-12 months after surgery & 135 & $35.7(30.9-40.6)$ & $2.24(1.65-3.06)$ & $<0.0001$ \\
\hline 13-24 months after surgery & 67 & $17.7(13.9-21.6)$ & $1.05(0.74-1.49)$ & 0.79 \\
\hline Hysterectomy & $(n=112)$ & & & \\
\hline 13-24 months before surgery & 20 & $17.9(10.7-25.1)$ & Reference & - \\
\hline 1-12 months before surgery & 42 & $37.5(28.4-46.6)$ & $2.26(1.29-3.95)$ & 0.004 \\
\hline 0-12 months after surgery & 34 & $30.4(21.7-39.0)$ & $1.78(1.002-3.18)$ & 0.049 \\
\hline 13-24 months after surgery & 21 & $18.8(11.4-26.1)$ & $1.05(0.56-1.99)$ & 0.87 \\
\hline Spinal fusion & $(n=61)$ & & & \\
\hline 13-24 months before surgery & 11 & $18.0(8.1-28.0)$ & Reference & - \\
\hline 1-12 months before surgery & 20 & $32.8(20.7-44.9)$ & $1.92(0.89-4.14)$ & 0.10 \\
\hline 0-12 months after surgery & 17 & $27.9(16.3-39.4)$ & $1.60(0.73-3.53)$ & 0.24 \\
\hline 13-24 months after surgery & 11 & $18.0(8.1-28.0)$ & $1.00(0.42-2.37)$ & 0.99 \\
\hline Mastectomy & $(n=30)$ & & & \\
\hline 13-24 months before surgery & 5 & $16.7(25.1-30.8)$ & Reference & - \\
\hline $1-12$ months before surgery & 11 & $36.7(18.4-55.0)$ & $2.34(0.78-6.98)$ & 0.13 \\
\hline $0-12$ months after surgery & 9 & $30.0(12.6-47.4)$ & $1.87(0.61-5.78)$ & 0.28 \\
\hline 13-24 months after surgery & 5 & $16.7(25.1-30.8)$ & $1.00(0.28-3.55)$ & 0.99 \\
\hline
\end{tabular}

$\mathrm{Cl}$ confidence interval, aOR adjusted odds ratio

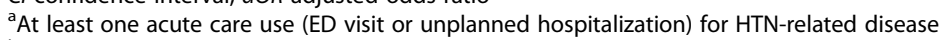

${ }^{b}$ Adjusted odds ratios are for each 12-month period versus the reference period (i.e., 13-24 months before surgery), as calculated with conditional

logistic regression 
present study have diverse racial/ethnic, socioeconomic, and geographic characteristics with the use of large population-based databases that capture all ED visits and hospitalizations in the studied states. This diversity in the study population strengthens the external validity of our inferences.

Possible differential effects according to age group and sex In the sensitivity analysis stratifying patients by age group, we observed similar risk reduction of acute care use for HTN-related disease after bariatric surgery in the younger populations. This finding is mirrored by a prior retrospective cohort study in patients who underwent bariatric surgery. That study reported that improvement in HTN control was observed in a significantly greater proportion of patients $<60$ years of age compared to patients $\geq 60$ years of age [34]. In addition, although we observed that the direction and effect size of bariatric surgery on the risk of acute care use for HTN-related disease during the first year after bariatric surgery was similar across female and male patients, the effect persisted longer in female patients. The potential reasons for this discrepancy are likely multifactorial, such as differences in health behaviors [35, 36], access to healthcare [37-40], pre-existent cardiovascular comorbidities [4143], or any combination of these factors [44]. For example, older and male patients might have had more established arterial atherosclerosis which would be less reversible with weight loss $[45,46]$. Our observations suggest that weight reduction achieved by bariatric surgery may not be sufficient to prevent $\mathrm{HTN}$-associated morbidities among older or male patients with HTN. The results of these stratified analyses underscore the importance of identifying underlying mechanisms that account for the differential effects of bariatric surgery and developing targeted strategies for the patient populations in whom bariatric surgery may be less effective.

\section{Accuracy of case, exposure, and outcome identification}

Although the HCUP databases have been widely used in the literature, and the quality has been extensively tested $[16-19,47]$, misclassification is possible as with any studies using administrative data. With regard to obesity, the specificity of the ICD-9-CM codes for obesity was reported to be $99.4 \%$ [48]. While the HCUP databases did not include data on body mass index, patients without obesity have therefore been excluded from our study [48]. Regarding the exposure, the method of identifying patients who underwent bariatric surgery has been used in several studies [16-20]. Moreover, it is well documented in the literature that bariatric surgery leads to substantial weight loss [49]. For example, prompt weight loss was observed within a few months after bariatric surgery and persisted for 12 to 18 months, with a mean weight loss of 35\% [49]. These data support the idea that bariatric surgery can be used as an effective method to achieve significant weight reduction. With respect to the outcome, the set of ICD-9-CM codes has been used in previously published studies, and this combination has been shown to have a specificity of $95 \%$ and a positive predictive value of $97 \%$ for identifying HTN-related ED visits [21, 22]. Thus, our outcome identification strategy has effectively excluded acute care use for conditions other than HTN-related disease.

\section{Potential limitations}

Our study has several potential limitations. First, the probability of exposure may have been affected by a previous outcome event - for instance, patients who had an acute care use for HTN-related disease during the pre-operative period would not have undergone bariatric surgery while blood pressure was poorly controlled. However, this would have decreased the risk in the presurgery period and hence biased the inferences toward the null [15]. Second, we determined the risk of acute care use for HTN-related disease by ED visits or unplanned hospitalizations [12]. Therefore, one might argue that there might have been a compensatory increase in less acute forms of healthcare utilization for HTN (e.g., walk-in clinic, urgent care, and other ambulatory care visits). However, we also observed a significant reduction in the risk of hospitalizations, arguing against this possibility. Third, patients might have been lost to follow-up after bariatric surgery, thereby downwardly biasing our estimates. However, the sensitivity analysis limiting to patients who were confirmed to be alive and living within the study states for at least 2 years after surgery showed consistent findings. Fourth, the HCUP database did not include several potentially useful parameters such as information on diet, exercise, medication use, and patient education. Therefore, one might surmise that the observed reduction in the risk may be a result of intensified HTN management during the perisurgical period and may not be unique to bariatric surgery. However, it would be difficult to postulate that the risk reduction was fully attributable to intensified antihypertensive treatment for the following reasons: (1) a number of prior studies have reported that the majority of patients were able to either discontinue or decrease the number of antihypertensive medications after bariatric surgery [2-6], (2) no reduction in the risk was observed among obese adults with HTN who underwent elective non-bariatric surgery, and (3) there was no signal of risk reduction immediately prior to bariatric surgery when the medical regimen for HTN was likely optimized. It is possible that medication compliance might have improved after bariatric surgery. Finally, the inferences from our study may not be generalizable to 
other countries with optimal access to and resources in the primary care setting.

\section{Conclusions}

This self-controlled case series study using large populationbased datasets from three US states demonstrated that bariatric surgery is associated with a significant reduction in the risk of acute care use for HTN-related disease among obese adults with HTN. However, a large proportion of obese adults with HTN would choose not to undergo bariatric surgery for various reasons, such as an absence of indications, lack of insurance coverage, and peri-surgical risk. Our data also underscore the importance of developing safe and effective noninvasive weight loss strategies for obese patients with HTN to relieve the large societal burden of acute care use for HTN-related disease. Such effort should progress in concert with public health interventions to primarily prevent obesity and HTN to begin with.

\section{Additional files}

Additional file 1: Number of patients and risk of acute care use for hypertension-related disease, stratified by age group. (DOCX 27 kb)

Additional file 2: Number of patients and risk of acute care use for hypertension-related disease, stratified by sex. (DOCX 27 kb)

Additional file 3: Rate ratios for acute care use for hypertension-related disease, using negative binomial regression model. (DOCX $26 \mathrm{~kb}$ )

Additional file 4: Number of patients and risk of acute care use for hypertension-related disease, with more restrictive definition. (DOCX $27 \mathrm{~kb}$ )

Additional file 5: Number of patients and risk of acute care use for hypertension-related disease with gastric bypass and gastric banding (DOCX $27 \mathrm{~kb}$ )

\section{Abbreviations \\ aOR: Adjusted odds ratio; Cl: Confidence interval; ED: Emergency department; HCUP: Healthcare Cost and Utilization Project; HTN: Hypertension; ICD-9-CM: International Classification of Diseases, Ninth Revision, Clinical Modification; RCT: Randomized controlled trial; SEDD: State Emergency Department Databases; SID: State Inpatient Databases}

\section{Acknowledgements}

Not applicable.

\section{Funding}

Dr. Shimada was supported in part by an unrestricted grant from the American Heart Association National Clinical and Population Research Award, an unrestricted grant from Honjo International Scholarship Foundation, and an unrestricted grant from Massachusetts General Hospital Executive Committee on Research Fund for Medical Discovery Award. The funding organizations did not have any role in the study design, collection, analysis, or interpretation of data, in writing of the manuscript, or in the decision to submit the article for publication. The researchers were independent from the funding organizations.

\section{Availability of data and materials}

The data that support the findings of this study are available from the Healthcare Cost and Utilization Project (http://www.hcup-us.ahrq.gov), but restrictions apply to the availability of these data, which were used under license for the current study, and so are not publicly available. Data are however available from the authors upon reasonable request and with permission of the Healthcare Cost and Utilization Project.

\section{Authors' contributions}

YJS, YT, and $\mathrm{KH}$ conceived the study and design. DFMB and $\mathrm{KH}$ acquired the data. YJS, YT, HI, DFMB, and KH analyzed and interpreted the data. YJS drafted the manuscript. YJS, YT, HI, DFMB, and $\mathrm{KH}$ critically revised the manuscript for important intellectual content. YJS and $Y T$ provided statistical expertise. $\mathrm{KH}$ provided study supervision. All authors read and approved the final manuscript.

\section{Ethics approval and consent to participate}

The institutional review board of Massachusetts General Hospital approved this study.

\section{Consent for publication}

Not applicable.

\section{Competing interests}

The authors declare that they have no competing interests.

\section{Publisher's Note}

Springer Nature remains neutral with regard to jurisdictional claims in published maps and institutional affiliations.

\section{Author details}

${ }^{1}$ Cardiology Division, Department of Medicine, Massachusetts General Hospital, Harvard Medical School, 55 Fruit Street, Gray/Bigelow 800, Boston, MA 02114, USA. ${ }^{2}$ Department of Health Policy and Management, Harvard T.H. Chan School of Public Health, 677 Huntington Ave, Boston, MA 02115, USA. ${ }^{3}$ Public Health, Department of Social Medicine, Osaka University Graduate School of Medicine, 1-1 Yamadaoka, Suita, Osaka 565-0871, Japan. ${ }^{4}$ Department of Emergency Medicine, Massachusetts General Hospital, Harvard Medical School, 55 Fruit Street, Boston, MA 02114, USA.

Received: 26 February 2017 Accepted: 11 July 2017

Published online: 23 August 2017

\section{References}

1. Kearney PM, Whelton M, Reynolds K, Muntner P, Whelton PK, He J. Global burden of hypertension: analysis of worldwide data. Lancet. 2005;365(9455): 217-23

2. Members WG, Mozaffarian D, Benjamin EJ, Go AS, Arnett DK, Blaha MJ, Cushman M, et al. American Heart Association Statistics Committee, Stroke Statistics Subcommittee: Heart disease and stroke statistics - 2016 update: a report from the American Heart Association. Circulation. 2016;133(4):e38-60.

3. Danaei G, Finucane MM, Lin JK, Singh GM, Paciorek CJ, Cowan MJ, Global Burden of Metabolic Risk Factors of Chronic Diseases Collaborating Group (Blood Pressure), et al. National, regional, and global trends in systolic blood pressure since 1980: systematic analysis of health examination surveys and epidemiological studies with 786 country-years and 5.4 million participants. Lancet. 2011;377(9765):568-77.

4. Czernichow S, Castetbon K, Salanave B, Vernay M, Barry Y, Batty GD, et al. Determinants of blood pressure treatment and control in obese people: evidence from the general population. J Hypertens. 2012;30(12):2338-44.

5. Flegal KM, Kruszon-Moran D, Carroll MD, Fryar CD, Ogden CL. Trends in obesity among adults in the United States, 2005 to 2014. JAMA. 2016; 315(21):2284-91.

6. Hall JC, Watts JM, O'Brien PE, Dunstan RE, Walsh JF, Slavotinek AH, et al. Gastric surgery for morbid obesity. The Adelaide Study. Ann Surg. 1990; 211(4):419-27.

7. Skroubis G, Anesidis S, Kehagias I, Mead N, Vagenas K, Kalfarentzos F. Rouxen-Y gastric bypass versus a variant of biliopancreatic diversion in a nonsuperobese population: prospective comparison of the efficacy and the incidence of metabolic deficiencies. Obes Surg. 2006;16(4):488-95.

8. van Dielen FM, Soeters PB, de Brauw LM, Greve JW. Laparoscopic adjustable gastric banding versus open vertical banded gastroplasty: a prospective randomized trial. Obes Surg. 2005;15(9):1292-8.

9. O'Brien PE, Dixon JB, Laurie C, Anderson M. A prospective randomized trial of placement of the laparoscopic adjustable gastric band: comparison of the perigastric and pars flaccida pathways. Obes Surg. 2005;15(6):820-6.

10. Wilhelm SM, Young J, Kale-Pradhan PB. Effect of bariatric surgery on hypertension: a meta-analysis. Ann Pharmacother. 2014;48(6):674-82. 
11. Gloy VL, Briel M, Bhatt DL, Kashyap SR, Schauer PR, Mingrone G, et al. Bariatric surgery versus non-surgical treatment for obesity: a systematic review and meta-analysis of randomised controlled trials. BMJ. 2013;347:f5934.

12. Vashi AA, Fox JP, Carr BG, D'Onofrio G, Pines JM, Ross JS, et al. Use of hospital-based acute care among patients recently discharged from the hospital. JAMA. 2013;309(4):364-71.

13. Overview of the State Emergency Department Databases (SEDD). Healthcare Cost and Utilization Project. 2017. http://www.hcup-us.ahrq.gov/ seddoverview.jsp. Accessed 7 July 2017.

14. Overview of the State Inpatient Databases (SID). Healthcare Cost and Utilization Project. 2017. http://www.hcup-us.ahrq.gov/sidoverview.jsp. Accessed 7 July 2017.

15. Whitaker HJ, Farrington CP, Spiessens B, Musonda P. Tutorial in biostatistics: the self-controlled case series method. Stat Med. 2006;25(10):1768-97.

16. Shimada YJ, Tsugawa Y, Brown DF, Hasegawa K. Bariatric surgery and emergency department visits and hospitalizations for heart failure exacerbation: population-based, self-controlled series. J Am Coll Cardiol. 2016;67(8):895-903.

17. Hasegawa K, Tsugawa Y, Chang Y, Camargo Jr CA. Risk of an asthma exacerbation after bariatric surgery in adults. J Allergy Clin Immunol. 2015; 136(2):288-94.e8.

18. Shimada YJ, Tsugawa Y, Iso H, Brown DFM, Hasegawa K. Association between bariatric surgery and risk of hospitalizations for stable angina pectoris in obese adults. Heart. 2017;103(13). doi:10.1136/heartjnl-2016310757.

19. Shimada YJ, Tsugawa Y, Camargo CA, Jr, Brown DFM, Hasegawa K: Effect of bariatric surgery on emergency department visits and hospitalizations for atrial fibrillation. Am J Cardiol. 2017. doi:10.1016/j.amjcard.2017.06.026.

20. Nguyen GC, Patel AM. Racial disparities in mortality in patients undergoing bariatric surgery in the U.S.A. Obes Surg. 2013;23(10):1508-14.

21. McNaughton $C D$, Self $W H$, Zhu Y, Janke AT, Storrow AB, Levy P. Incidence of hypertension-related emergency department visits in the United States, 2006 to 2012. Am J Cardiol. 2015;116(11):1717-23.

22. Birman-Deych E, Waterman AD, Yan Y, Nilasena DS, Radford MJ, Gage BF. Accuracy of ICD-9-CM codes for identifying cardiovascular and stroke risk factors. Med Care. 2005;43(5):480-5.

23. Dimick JB, Nicholas LH, Ryan AM, Thumma JR, Birkmeyer JD. Bariatric surgery complications before vs after implementation of a national policy restricting coverage to centers of excellence. JAMA. 2013;309(8):792-9.

24. Ashrafian H, le Roux CW, Darzi A, Athanasiou T. Effects of bariatric surgery on cardiovascular function. Circulation. 2008;118(20):2091-102.

25. Klein S. Outcome success in obesity. Obes Res. 2001;9 Suppl 4:354S-8S.

26. Hankey CR, Lean ME, Lowe GD, Rumley A, Woodward M. Effects of moderate weight loss on anginal symptoms and indices of coagulation and fibrinolysis in overweight patients with angina pectoris. Eur J Clin Nutr. 2002;56(10):1039-45.

27. Karason K, Wallentin I, Larsson B, Sjostrom L. Effects of obesity and weight loss on left ventricular mass and relative wall thickness: survey and intervention study. BMJ. 1997;315(7113):912-6.

28. Jensen MD, Ryan DH, Apovian CM, Ard JD, Comuzzie AG, Donato KA, et al. American College of Cardiology/American Heart Association Task Force on Practice Guidelines, Obesity Society: 2013 AHA/ACC/TOS guideline for the management of overweight and obesity in adults: a report of the American College of Cardiology/American Heart Association Task Force on Practice Guidelines and The Obesity Society. J Am Coll Cardiol. 2014;63(25 Pt B): 2985-3023.

29. Chang SH, Stoll CR, Song J, Varela JE, Eagon CJ, Colditz GA. The effectiveness and risks of bariatric surgery: an updated systematic review and meta-analysis, 2003-2012. JAMA Surg. 2014;149(3):275-87.

30. Maasland L, van Oostenbrugge RJ, Franke CF, Scholte Op Reimer WJ, Koudstaal PJ, Dippel DW. Netherlands Stroke Survey Investigators. Patients enrolled in large randomized clinical trials of antiplatelet treatment for prevention after transient ischemic attack or ischemic stroke are not representative of patients in clinical practice: the Netherlands Stroke Survey. Stroke. 2009;40(8):2662-8.

31. Van Spall HG, Toren A, Kiss A, Fowler RA. Eligibility criteria of randomized controlled trials published in high-impact general medical journals: a systematic sampling review. JAMA. 2007;297(11):1233-40.

32. Halperin F, Ding SA, Simonson DC, Panosian J, Goebel-Fabbri A, Wewalka M, et al. Roux-en-Y gastric bypass surgery or lifestyle with intensive medical management in patients with type 2 diabetes: feasibility and 1-year results of a randomized clinical trial. JAMA Surg. 2014;149(7):716-26.

33. Ikramuddin S, Korner J, Lee WJ, Connett JE, Inabnet WB, Billington CJ, et al. Roux-en-Y gastric bypass vs intensive medical management for the control of type 2 diabetes, hypertension, and hyperlipidemia: the Diabetes Surgery Study randomized clinical trial. JAMA. 2013;309(21):2240-9.

34. Busetto L, Angrisani L, Basso N, Favretti F, Furbetta F, Lorenzo M, Italian Group for Lap-Band. Safety and efficacy of laparoscopic adjustable gastric banding in the elderly. Obesity. 2008;16(2):334-8.

35. van Hout GC, Verschure SK, van Heck GL. Psychosocial predictors of success following bariatric surgery. Obes Surg. 2005;15(4):552-60.

36. Balan H, Popescu L. "Gender specific medicine": a focus on genderdifferences in hypertension. Rom J Intern Med. 2014;52(3):129-41.

37. Fortuna RJ, Robbins BW, Halterman JS. Ambulatory care among young adults in the United States. Ann Intern Med. 2009;151(6):379-85.

38. Jorgensen JT, Andersen JS, Tjonneland A, Andersen ZJ. Determinants related to gender differences in general practice utilization: Danish Diet, Cancer and Health Cohort. Scand J Prim Health Care. 2016;34:240-9.

39. Vaidya V, Partha G, Karmakar M. Gender differences in utilization of preventive care services in the United States. J Womens Health. 2012;21(2):140-5.

40. Viera AJ, Thorpe JM, Garrett JM. Effects of sex, age, and visits on receipt of preventive healthcare services: a secondary analysis of national data. BMC Health Serv Res. 2006;6:15.

41. Journath G, Hellenius ML, Petersson U, Theobald H, Nilsson PM. Hyper-Q Study Group Sweden. Sex differences in risk factor control of treated hypertensives: a national primary healthcare-based study in Sweden. Eur J Cardiovasc Prev Rehabil. 2008;15(3):258-62.

42. Nilsson PM, Theobald H, Journath G, Fritz T. Gender differences in risk factor control and treatment profile in diabetes: a study in 229 Swedish primary health care centres. Scand J Prim Health Care. 2004;22(1):27-31.

43. Ong KL, Tso AW, Lam KS, Cheung BM. Gender difference in blood pressure control and cardiovascular risk factors in Americans with diagnosed hypertension. Hypertension. 2008;51(4):1142-8.

44. Pradhan AD. Sex differences in the metabolic syndrome: implications for cardiovascular health in women. Clin Chem. 2014;60(1):44-52.

45. Montero D, Roberts CK, Vinet A. Effect of aerobic exercise training on arterial stiffness in obese populations: a systematic review and metaanalysis. Sports Med. 2014;44(6):833-43.

46. Safar ME, Thomas F, Blacher J, Nzietchueng R, Bureau JM, Pannier B, et al. Metabolic syndrome and age-related progression of aortic stiffness. J Am Coll Cardiol. 2006:47(1):72-5.

47. Hasegawa K, Tsugawa Y, Brown DF, Camargo Jr CA. A population-based study of adults who frequently visit the emergency department for acute asthma. California and Florida, 2009-2010. Ann Am Thorac Soc. 2014;11(2):158-66.

48. Goff SL, Pekow PS, Markenson G, Knee A, Chasan-Taber L, Lindenauer PK. Validity of using ICD-9-CM codes to identify selected categories of obstetric complications, procedures and co-morbidities. Paediatr Perinat Epidemiol. 2012;26(5):421-9.

49. Buchwald $H$, Avidor $Y$, Braunwald $E$, Jensen MD, Pories W, Fahrbach $K$, et al. Bariatric surgery: a systematic review and meta-analysis. JAMA. 2004;292(14): 1724-37.

\section{Submit your next manuscript to BioMed Central and we will help you at every step:}

- We accept pre-submission inquiries

- Our selector tool helps you to find the most relevant journal

- We provide round the clock customer support

- Convenient online submission

- Thorough peer review

- Inclusion in PubMed and all major indexing services

- Maximum visibility for your research

Submit your manuscript at www.biomedcentral.com/submit 